\title{
An Investigation on Biological Efficacies of Fruits and Leaves of Ficus auriculata (Timilo) from Kanchanpur District, Nepal
}

\author{
Bishan Datt Bhatt*, Dharma Raj Joshi* \\ Department of Chemistry, Tri-Chandra Multiple Campus, Tribhuvan University, Nepal \\ *E-mail: bdbhatta@gmail.com; dharmarajjoshi44@gmail.com
}

(Received:7 April 2021, Received in revised form: 16 April, Accepted: 29 June 2021, Available Online)

\section{Highlights}

- Different solvent extracts of Ficusauriculata leaves and unripe fruits were obtained using a Soxhlet extractor.

- The extracts were subjected to phytochemical screening, antibacterial activity analysis and antioxidant activity analysis.

- Significant antibacterial and antioxidant activity have been found. The Fruits have been found to possess higher antioxidant activity than leaves.

\begin{abstract}
Ficus auriculata is a native Asian plant found in the temperate, tropical and subtropical regions and has been commonly used in traditional medicine and as fodder in animal husbandry. The comparative antibacterial and antioxidant efficacies of leaves and fruits have been studied using their hexane, chloroform, ethyl acetate and methanol extracts. Phytochemical screening exhibited the presence of important secondary metabolites like alkaloids, carbohydrates, glycosides, flavonoids and tannins. Antibacterial activities of fruit and leaf extracts in different concentrations were studied against E. coli, S. aureus and S. typhi by agar well diffusion method. The highest inhibition was found to be in 1\% methanol extracts of leaves and fruits with a zone of inhibition (ZOI) $\pm 16 \mathrm{~mm}$ against $S$. aureus followed by E. coli and S. typhi with ZOI $\pm 14 \mathrm{~mm}$. The crude and $50 \%$ extracts of various solvents of both fruits and leaves were found to be ineffective against bacteria. These results reveal that there is a significant antibacterial activity in methanol extract of both fruit and leaves, against gram-positive and gram-negative bacteria. The antioxidant activities of methanol extracts of fruits and leaves were studied by DPPH radical scavenging assay. The IC ${ }_{50}$ values of methanol extract of leaves and fruit for DPPH radical scavenging assay were found to be $114.84 \mu \mathrm{g} / \mathrm{mL}$ and $78.28 \mu \mathrm{g} /$ $m L$, respectively. These results reveal that methanol fruit extract exhibits better antioxidant activity as compared to the leaves.
\end{abstract}

The result of this investigation has revealed the applicability of this plant as a potential source of several bioactive compounds for the discovery of new and efficacious drugs in days to come.

Keywords: Ficus auriculata, phytochemical, antioxidant, antibacterial, zone of inhibition

\section{Introduction}

From ancient times, natural products from terrestrial plants, animal products, marine organisms and products of microorganismal fermentation have been used in traditional medicines. This experience on the therapeutic use of natural products has led to the development of sophisticated isolation techniques for bioactive compounds and drug discovery using ethnopharmacological plants [1]. In Nepal, 701 species of medicinal plants are reported till now, while 7000 species of flowering plants from Nepal are reported to have medicinal properties [2]. In the Far western region of Nepal, medicinal herbs are the main ingredients of traditional therapies used as first choice [3].

${ }^{*}$ Corresponding author 
Ficus auriculata belongs to the family Moraceae. It generally grows in the temperate and subtropical regions of Asia at about 1800-2600 m altitude. It grows best in the area with an annual temperature of 15-20 ${ }^{\circ} \mathrm{C}$ and rainfall of 1200-1900 mm but can withstand $12-39^{\circ} \mathrm{C}$ temperature and $900-2400 \mathrm{~mm}$ rain. The family Moraceae consists of 800 species with 40 genres. Among them, 511 occur in Indo-Australian region (Asia, Malaysia, Pacific Islands and Australia) and approximately in 132 in tropical region (Central and South America) [4]. It has different names in Nepal in different ethnic groups. In Nepal, it is known by various names like nimaro, timilo, timila, anjir, gopa or bhutuk in Nepali language, kaitak in Chepang, paingi in Gurung, payepa in Limbu and Mago in Tamang language [5]. This plant has been used in Nepali society for ages as the local remedy for various diseases. Local people of Nepal use tree leaves as fodder for animal husbandry. Due to the large size of leaves, they are also used to make plates (tapari). Research has shown that, out of 36 native ficus species, 21 are indigenously used as food, fodder, fuelwood, vegetable and medicine. Some figs like pipal (F. religiouosa), bar (F. Benjamin) and dumri (F. recemos) are used religiously in Nepal [6]. Young tender shoots are used in Nepali cuisine to make vegetables. The unripe figs are pickled and ripe figs are eaten raw [7]. Tender shoots and fruits are used to cure dysentery and diarrhoea in the Parsa district of Nepal [8]. Juice of F. semicordata root is given in the treatment of menstrual disorders [9]. Various Ficus species are used as folk medicines for the treatment of asthma, cough, sexual disorder, diarrhea, earache, and toothache [10]. In Bangladesh, leaves are crushed and its paste is applied for healing wounds. Roasted figs are taken against diarrhoea and dysentery. Latex or the root of this plant has been used for the treatment of cholera diarrhoea, mumps and vomiting. Fruits of figs have relatively higher amount of minerals than exotic fruits. When compared to mango and jack fruits, it has been reported that most of the wild fig species contain higher amount of minerals and vitamins [11].

The important organic compounds like lupeol, betulinic acid, bergapten, stigmasterol, $\beta$-sitosterol-3-O- $\beta$-D-glucopyranoside, myricetin, scopoletin and quercetin-3-O- $\beta$-D-glucopyranoside have been isolated from the leaves and fruits of Ficus auriculata [12]. Ficus species are rich in polyphenolic compounds and flavonoids, which are responsible for strong antioxidant activity, which help in the prevention and therapy of various oxidative stresses such as neurodegenerative and hepatic diseases [13]. Significant antibacterial and antioxidant activity have been reported in the barks of $F$. auriculata [4]. Therefore, the study on biological efficacy of the other parts of this plant becomes imperative. As far as the authors' present knowledge is concerned, no research work has been carried out to analyze the comparative biological efficacies of leaves and fruits of this plant. The present study has been carried out to fulfil the aforementioned gap and provide important input in the field of natural product chemistry. In the present work, the comparative antibacterial and antioxidant efficacies of leaves and fruits of Ficus Auriculata have been studied using their hexane, chloroform, ethyl acetate and methanol extracts.

\section{Materials and Methods}

\section{Collection of plant}

The leaves and unripe fruits of Ficus auriculata were collected in the month of July from the Bedkot municipality of Kanchanpur district, Nepal. The plant materials were identified by the Department of Botany, Tri-Chandra Multiple Campus. They were washed, shade dried and crushed into fine powder using mortar.

\section{Extraction of plant materials}

The powdered leaves and fruits were subjected to extraction using a Soxhlet extractor with the solvent hexane, chloroform, ethyl acetate and methanol successively at $30{ }^{\circ} \mathrm{C}$. Then the extracts were collected separately, evaporated using a rotatory evaporator, and the dry extracts were used for further study.

\section{Phytochemical analysis}

The method employed for phytochemical screening was color-based reaction procedure [14]. Various tests like Mayer's test for alkaloid, Fehling test for carbohydrate, Legal test for Glycosides, Lead acetate test for Flavonoids, Lead acetate test for tannins, Froth test for saponins and Salkowski test for steroids were performed to detect secondary metabolites.

\section{Antibacterial activity test}

Antibacterial activity of the plant extract was performed by the agar well diffusion method [15]. The effectiveness of antibacterial activity was evaluated by determining the zone of inhibition (ZOI). The microbial strains obtained from MED- 
MICRO Nepal laboratory, Kathmandu were inoculated in an agar medium. The studied strains included gram-positive bacterium (Staphylococcus aureus ATCC 25923) Cocci-grapes like structure, a Gram-negative bacterium (Escherichia coli ATCC 25922) short rod-shaped structure and another gram-negative bacterium (Salmonella typhi) pink in color. Six wells having the diameter of $6 \mathrm{~mm}$ were made in each incubated medium with the help of sterile cork-borer No. 6. Extracts of leaves and fruits were divided into four different concentrations. The $1 \%$ solution was made by transferring $0.01 \mathrm{~g}$ of each crude extract to a sterile vile having Dimethyl Sulfoxide (DMSO) solvent and the compound was dissolved. Similarly, 10\% and 50\% working solutions were made by transferring $0.1 \mathrm{~g}$ and $0.5 \mathrm{~g}$ crude extracts to $1 \mathrm{~mL}$ of DMSO solvent. The Muller Hinton agar was used as a nutrition broth. The $50 \mu \mathrm{L}$ of the working solution of the plant extract, DMSO as the negative control (NC) and $25 \mu \mathrm{L}$ of ofloxacin (antibiotic) as the positive control (PC) were loaded in the respective wells at the same time with the help of micropipette. The plates were left for the diffusion of an extract with media for half an hour with their lid closed. These plates were then incubated at a temperature of $37^{\circ} \mathrm{C}$ for 24 hours. After 24 hours of incubation, the plates were observed for the presence of inhibition of growth of bacteria, indicated by clear zone around the wells. The size of the zone of inhibition was measured, and the antibacterial activity was expressed in terms of an average diameter of the zone of inhibition in millimeter. The absence of the zone of inhibition was interpreted as the absence of the activity. The ZOI was measured with the help of a millimeter ruler, and the mean was recorded.

\section{Antioxidant activity test}

Antioxidants are the compounds which protect the cell against damage by the effect of reactive species. They also prevent the production of such reactive species and help in repairing the cell which has undergone oxidative damages [16]. An imbalance between antioxidants and reactive oxygen species causes oxidative stress leading to cellular damage, which ultimately leads to several pathophysiological conditions in the body [17]. Reactive oxygen species are highly reactive and unstable ions formed inside living organisms by oxidative stress, cell metabolic processes, pollutants and free radicals. These reactive oxygen species are very harmful as they react with various cellular components like DNA, proteins, lipids and fatty acids. This ultimately leads to various life-threatening conditions like cancer, inflammation and cardiovascular diseases due to the alteration in cell components [18].

Varying results of antioxidant activity can be obtained depending on the specific free radical being used as a reactant in different methods of its measurement. One of the efficient methods for the same is the use of a free radical, 2,2-diphenyl-1picrylhydrazyl (DPPH). The DPPH is scavenged by antioxidants through the donation of proton forming the reduced DPPH. DPPH solution shows a strong absorbance band at $517 \mathrm{~nm}$, appearing as a deep violet color. The changes in color from purple to yellow takes place due to reduction, which is quantitatively measured by the decrease in absorbance at wavelength $517 \mathrm{~nm}$. The degree of de-colorization indicates the free radical scavenging potential.

The antioxidant activity of the methanol extract was measured by DPPH radical scavenging assay [19]. Solutions of concentration of $0.02 \mathrm{mg} / \mathrm{mL}, 0.04 \mathrm{mg} / \mathrm{mL}, 0.06 \mathrm{mg} / \mathrm{mL}, 0.08 \mathrm{mg} / \mathrm{mL}$, and $0.1 \mathrm{mg} / \mathrm{mL}(0.02-0.1)$ were prepared for leaf and fruit extract dissolving in methanol. A freshly prepared $10 \mathrm{~mL} \mathrm{DPPH} \mathrm{solution} \mathrm{was} \mathrm{mixed} \mathrm{with} 20 \mathrm{~mL}$ of the above mention solutions. As a positive control, solutions of the same concentrations of ascorbic acid were taken. Absorbance was measured at $517 \mathrm{~nm}$ after 15 minutes. The lower value of absorbance by the reaction mixture specifies the higher radical scavenging activity. The presence of DPPH free radical scavenging activity was calculated by using the following equation:

Radical scavenging $(\%)=\left[\left(\mathrm{A}_{0}-\mathrm{A}_{\mathrm{s}}\right) / \mathrm{A}_{0}\right] \times 100$

Where, $\mathrm{A}_{0}=$ Absorbance of the control (DPPH solution + methanol),

$\mathrm{A}_{\mathrm{S}}=$ Absorbance of the test sample

$\mathrm{The}_{50}(50 \%$ inhibitory concentration) value indicates the effective concentration of the sample, which is required to scavenge $50 \%$ of the DPPH free radicals. The inhibition curve was plotted by plotting extract concentration versus the corresponding scavenging effect, and the plot was used to calculate $\mathrm{IC}_{50}$ values. The low value of $\mathrm{IC}_{50}$ refers to the strong antioxidant activity [4].

\section{Results and Discussion}

\section{Percentage yield}

The percentage yields of different solvent extracts obtained have been presented in table 1 . 
Table 1: Percentage yield of different extracts of fruit and leaves of F. auriculata

\begin{tabular}{|c|c|l|c|c|c|}
\hline S.N & Part of plant & \multicolumn{1}{|c|}{ Solvent } & Quantity taken $(\mathrm{g})$ & Quantity of extract (g) & Percentage yield (\%) \\
\hline 1 & Leaves & Hexane & 300 & 2.5 & 0.833 \\
\hline 2 & Leaves & Chloroform & 280 & 1.8 & 0.644 \\
\hline 3 & Leaves & Ethyl acetate & 270 & 2.0 & 0.740 \\
\hline 4 & Leaves & Methanol & 260 & 2.2 & 0.846 \\
\hline 5 & Fruits & Hexane & 300 & 1.8 & 0.600 \\
\hline 6 & Fruits & Chloroform & 280 & 1.7 & 0.607 \\
\hline 7 & Fruits & Ethyl acetate & 260 & 2.0 & 0.769 \\
\hline 8 & Fruits & Methanol & 250 & 2.0 & 0.800 \\
\hline
\end{tabular}

Methanol solvent has a higher percentage yield of crude extract as compared to the other solvents. Methanol is a polar solvent and most of the secondary metabolites obtained are also polar compounds. Since most antibacterial and antioxidant activity are shown by methanol extract rather than extract of other non-polar solvent like hexane, methanol is highly recommended as a solvent for the extraction process.

\section{Phytochemical analysis}

The various phytochemicals in the extracts were determined according to standard phytochemical screening methods, where the color changes in the different reagents by the extracts were observed. The fundamental purpose of phytochemical screening was to find the types of chemical constituents present in the different plant extracts. The main phytochemicals observed as a result of the phytochemical screening of the leaves and fruit of Ficus auriculata have been summarized in table 2 .

Table 2: Phytochemical constituents of different solvent extracts of fruit and leaves of Ficus auriculata.

\begin{tabular}{|c|l|c|c|c|c|}
\hline S.N & Phytochemical test & Hexane extract & Chloroform extract & Ethyl acetate extract & Methanol extract \\
\hline 1 & Alkaloid test & + & + & + & + \\
\hline 2 & Carbohydrate test & + & + & + & + \\
\hline 3 & Glycoside test & + & + & + & + \\
\hline 4 & Flavonoid test & - & + & + & + \\
\hline 5 & Tannin test & + & - & - & - \\
\hline 6 & Saponin test & - & - & - & - \\
\hline 7 & Steroid test & - & & + \\
\hline
\end{tabular}

The phytochemical screening showed the presence of alkaloids, carbohydrates, glycosides, flavonoids and tannins. The above results show that almost all phytochemicals except saponins and steroids are present in all the extracts. The presence of some polar compounds even in hexane extract might be due to the presence of some polar compounds having large-sized molecules, which possess large hydrophobic parts in their molecules. These data suggest that the plant can be used as a potential source of different natural products.

\section{Antibacterial activity}

The antibacterial activities of the plant extracts of different concentrations were analyzed in the selected bacteria by measuring the zone of inhibition values. The zone of inhibition (ZOI) values of different solvent extracts of fruits and leaves have been reported in tables 3-8. 
Table 3: Zone of inhibition (ZOI) by extracts against E.Coli for ofloxacin standard (mm) for leaves.

\begin{tabular}{|l|c|c|c|c|c|c|}
\hline Extract & P.C & Solvent & Crude & $50 \%$ & $10 \%$ & $1 \%$ \\
\hline Hexane & 30 & 12 & 0 & 16 & 0 & 0 \\
\hline chloroform & 26 & 9 & 0 & 0 & 10 & 12 \\
\hline Ethyl acetate & 25 & 11 & 0 & 0 & 13 & 13 \\
\hline Methanol & 30 & 10 & 0 & 0 & 13 & 14 \\
\hline
\end{tabular}

Table 4: Zone of inhibition (ZOI) by extracts against E. Coli for ofloxacin standard (mm) for fruits

\begin{tabular}{|l|c|c|c|c|c|c|}
\hline Extract & P.C & Solvent & Crude & $50 \%$ & $10 \%$ & $1 \%$ \\
\hline Hexane & 30 & 12 & 0 & 0 & 0 & 0 \\
\hline chloroform & 26 & 9 & 0 & 0 & 13 & 10 \\
\hline Ethyl acetate & 25 & 11 & 0 & 0 & 12 & 13 \\
\hline Methanol & 30 & 10 & 0 & 0 & 13 & 14 \\
\hline
\end{tabular}

Table 5: Zone of inhibition (ZOI) by extracts against S.Aureus for ofloxacin standard (mm) for leaves.

\begin{tabular}{|l|c|c|c|c|c|c|}
\hline Extract & P.C & Solvent & Crude & $50 \%$ & $10 \%$ & $1 \%$ \\
\hline Hexane & 29 & 0 & 10 & 12 & 0 & 0 \\
\hline chloroform & 27 & 0 & 0 & 0 & 11 & 0 \\
\hline Ethyl acetate & 27 & 0 & 0 & 0 & 12 & 10 \\
\hline Methanol & 32 & 0 & 0 & 0 & 15 & 16 \\
\hline
\end{tabular}

Table 6: Zone of inhibition (ZOI) by extracts against S.Aureus for ofloxacin standard (mm) for fruits.

\begin{tabular}{|l|c|c|c|c|c|c|}
\hline Extract & P.C & Solvent & Crude & $\mathbf{5 0 \%}$ & $\mathbf{1 0 \%}$ & $\mathbf{1 \%}$ \\
\hline Hexane & 29 & 0 & 0 & 12 & 0 & 0 \\
\hline chloroform & 28 & 0 & 0 & 0 & 10 & 12 \\
\hline Ethyl acetate & 28 & 0 & 0 & 0 & 12 & 10 \\
\hline Methanol & 32 & 0 & 0 & 0 & 15 & 16 \\
\hline
\end{tabular}

Table 7: Zone of inhibition (ZOI) by extracts against S. typhi for ofloxacin standard (mm) for leaves.

\begin{tabular}{|l|c|c|c|c|c|c|}
\hline Extract & P.C & Solvent & Crude & $\mathbf{5 0 \%}$ & $\mathbf{1 0 \%}$ & $\mathbf{1 \%}$ \\
\hline Hexane & 32 & 10 & 11 & 12 & 0 & 0 \\
\hline chloroform & 32 & 10 & 0 & 0 & 14 & 12 \\
\hline Ethyl acetate & 32 & 9 & 0 & 0 & 14 & 13 \\
\hline Methanol & 30 & 10 & 0 & 0 & 13 & 15 \\
\hline
\end{tabular}

Table 8: Zone of inhibition (ZOI) by extracts against S.typhi for ofloxacin standard (mm) for fruits.

\begin{tabular}{|l|c|c|c|c|c|c|}
\hline Extract & P.C & Solvent & Crude & $50 \%$ & $10 \%$ & $1 \%$ \\
\hline Hexane & 32 & 10 & 12 & 11 & 0 & 0 \\
\hline chloroform & 32 & 10 & 0 & 0 & 13 & 15 \\
\hline Ethyl acetate & 32 & 9 & 0 & 0 & 14 & 14 \\
\hline Methanol & 30 & 10 & 0 & 0 & 13 & 15 \\
\hline
\end{tabular}


Photograph of Petri dishes showing zone of inhibition by various extracts using agar well diffusion method has been displayed in figure 1.

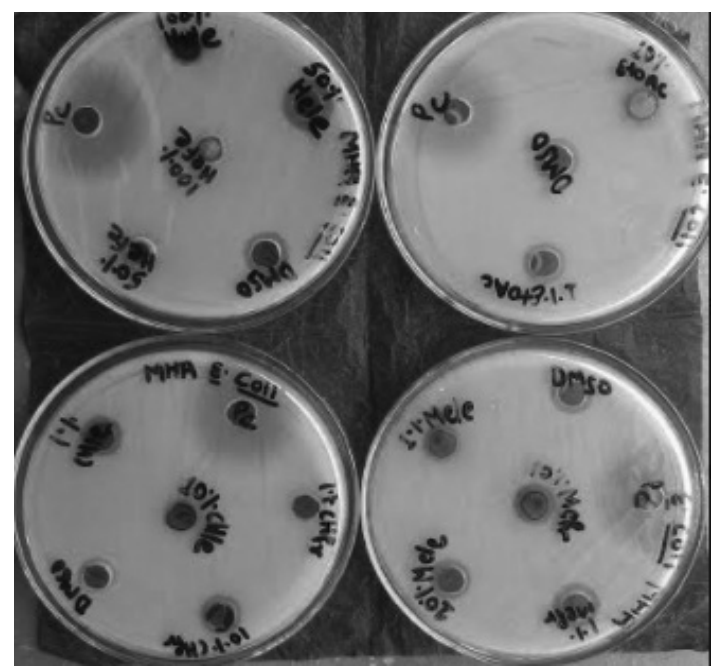

Fig 1: Photograph of Petri dishes showing zone of inhibition

Antibacterial activity was found to be high in $1 \%$ concentration of methanol extract against all three bacteria used. Crude and $50 \%$ extract of chloroform, ethyl acetate and methanol did not exhibit antibacterial activity but $1 \%$ and $50 \%$ hexane extract gave antibacterial test. The $50 \%$ hexane extract of leaves showed inhibition against all bacteria with the highest ZOI \pm 16 against $E$. coli. The $50 \%$ hexane fruit extract did not show inhibition against $E$. coli, but it was found to show inhibition against $S$. aureus and $S$. typhi. The $1 \%$ chloroform extract of fruit showed the highest inhibition against $S$. typhi with ZOI \pm 15 , whereas $10 \%$ chloroform leaf extract showed the highest inhibition against $S$. typhi with ZOI $\pm 14.1 \%$. The $10 \%$ ethyl acetate extract of fruit and leaves showed highest inhibition against $S$. typhi with ZOI \pm 14 , while inhibition against other bacteria by fruit and leave extracts were very close. The $10 \%$ and $1 \%$ methanol extracts of both fruit and leaves showed the same inhibition against all bacteria. The highest inhibition was shown by $1 \%$ methanol extract of leaves and fruit, which is $\pm 16 \mathrm{~mm}$ against gram-positive bacteria $S$. aureus, followed by E. coli and S. typhi.

The E. coli is the causative agent of diarrhoea and urinary tract infection, while $S$. aureus is the causative agent of skin infection, pimples, boils and scaled skin syndrome. Similarly, S. typhi is the causative agent of typhoid fever, food poisoning and gastroenteritis. Since fruits and leaves show positive results against these three bacteria, these parts of the plants can be used as homemade medicine for the above-mentioned diseases and infections.

\section{DPPH free radical scavenging activity}

The DPPH radical assay was performed for the determination of $\mathrm{IC}_{50}$ in methanol plant extract as well as in ascorbic acid. Since the phytochemical screening showed most of the polar compounds in methanol extract only, the methanol extract was taken for the DPPH radical assay. For comparison, the percentage of free radical scavenging activities under different concentrations of plant extracts and ascorbic acid have been graphically shown in Figure 2 and Figure 3.

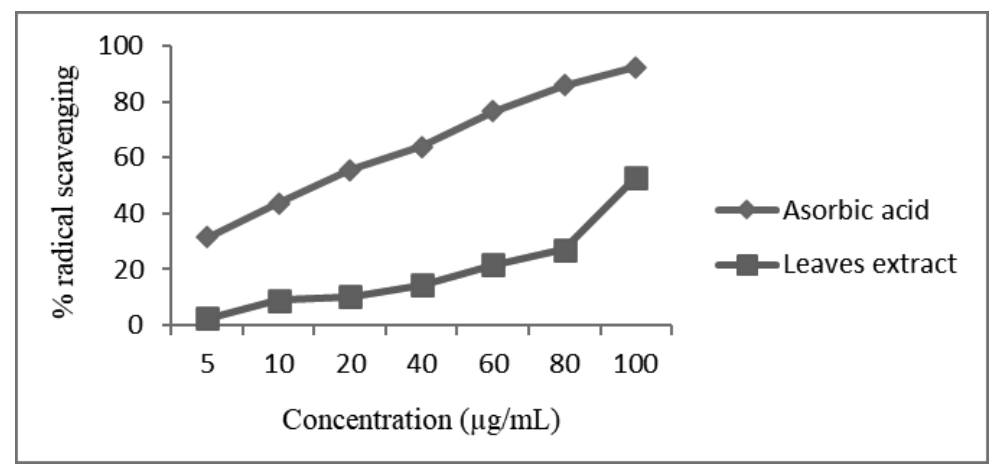

Fig 2: Comparison of \% free radical scavenging of ascorbic acid and methanol leaf extract 


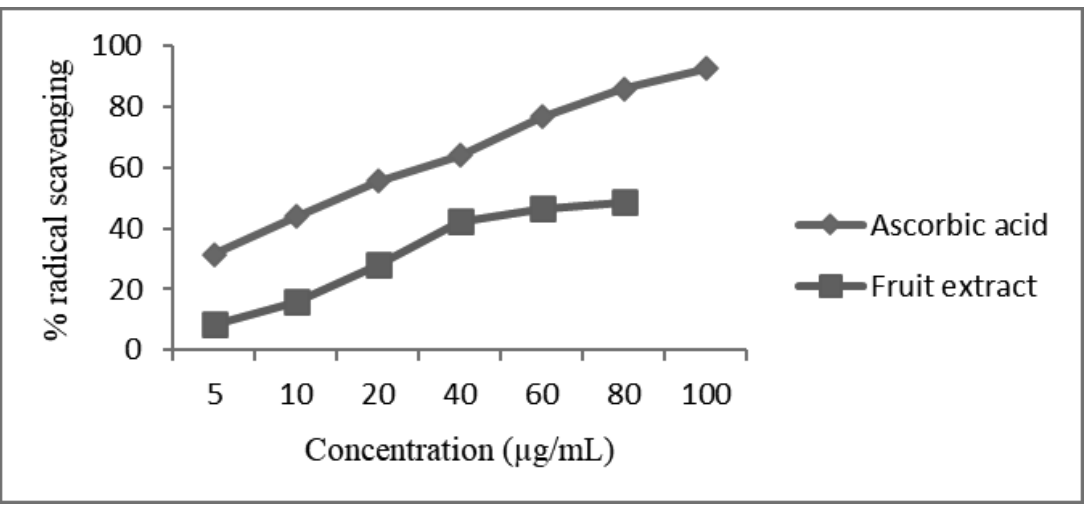

Fig 3: Comparison of \% free radical scavenging of ascorbic acid and methanol fruit extract

The antioxidant potential is in an inverse relation with $\mathrm{IC}_{50}$ value. A lower value of $\mathrm{IC}_{50}$ indicates the higher antioxidant potential. The $\mathrm{IC}_{50}$ values have been computed using the percentage radical scavenging versus concentration curves. The $\mathrm{IC}_{50}$ values of plant extracts along with standard ascorbic acid have been tabulated in table 9 .

Table 9: $I C_{50}$ values of methanol plant extracts and ascorbic acid.

\begin{tabular}{|l|l|l|}
\hline S.N & Sample & $\mathrm{IC}_{50}(\mu \mathrm{g} / \mathrm{mL})$ \\
\hline 1. & Ascorbic acid & 31.07 \\
\hline 2. & Leaf extract & 114.84 \\
\hline 3. & Fruit extract & 78.24 \\
\hline
\end{tabular}

$\mathrm{The}_{\mathrm{IC}}$ value of leaf extract has been found to be $114.84 \mu \mathrm{g} / \mathrm{mL}$. Similarly, the $\mathrm{IC}_{50}$ value of fruit extract has been found to be $78.24 \mu \mathrm{g} / \mathrm{mL}$. Above data shows that the antioxidant potentiality of fruit extract is higher than that of leaf extract as the $\mathrm{IC}_{50}$ value is less in the fruit extract. This again reveals the greater applicability of the fruit of this plant as a potential source of antioxidants as compared to the leaves.

\section{Conclusions}

Phytochemical screening, antioxidant activity and antibacterial activity were analyzed in various solvent extracts of fruits and leaves of $F$. auricualta. Color reaction method was used to detect the presence of phytochemicals. The present study revealed that various phytochemicals like alkaloids, carbohydrates, tannins and flavonoids are present in all the solvent extracts of fruits and leaves of this plant. Since, these secondary metabolites are very useful owing their antibacterial and antioxidant efficacies, the plant can be used as a potential source of various drugs.

Agar well method was used to analyze the antibacterial activity through the determination of zone of inhibition values in various solvent extracts of fruits and leaves. Antibacterial activity study revealed a substantial antibacterial potency of fruits and leaves of this plant. But, ZOI against both gram-positive and gram-negative bacteria vary with the change in the concentration of the extracts. These ZOI results vouch the application of this plant as a potential source of various antibacterial drugs.

DPPH radical scavenging method was used to investigate antioxidant activity of methanol extract, and the data of DPPH radical scavenging assay were expressed in terms of $\mathrm{IC}_{50}$ values. The antioxidant efficacy of methanol extract of fruit was found to be higher $\left(\mathrm{IC}_{50}=78.24 \mu \mathrm{g} / \mathrm{mL}\right)$ than that of methanol leaf extract $\left(\mathrm{IC}_{50}=111.84 \mu \mathrm{g} / \mathrm{mL}\right)$. The results reveal that fruits of $\mathrm{F}$. auriculata have higher antioxidant efficacy as compared to its leaves.

The methanol fruit extract is found to show significant antioxidant activity and thus the plant, especially its fruits, can be used as a potential source of antioxidants. The study also revealed that $F$. auriculata has a substantial potential as a source of antibacterial drugs against both gram-positive and gram-negative bacteria. Since large population of world is still dependent upon traditional medicine, further investigations can guide the use of fruits and leaves of this plant as commercial medicine to cure diseases. Apart from medicinal aspects, the nutritional value of leaves for animal husbandry and the nutritional value of fruit to cope starvation and malnutrition can be further scope of the study in this plant. 


\section{References}

1. M. Shibata, I.A. Khan, M. Iinuma, T. Shirai. Natural Products of Medicine, BioMed Research International, 2012. (DOI: https://doi.org/10.1155/2012/147120).

2. B.D. Bhatt, C. Chhetry. Comparative Study of Antioxidant and Antibacterial Activities in the Methanol and Ethyl Acetate Extract of Leaf and Stem Bark of Semecarpus anacardium Linn, Journal of Nepal Chemical Society, 2018, 38, 58-65. (DOI: https://doi.org/10.3126/jncs.v38i0.27789).

3. R.M. Kunwar, L. Mahat, R.P. Acharya, R.W. Bussmann. Medicinal Plants Traditional Medicine Markets \& Management in Far-West Nepal, Journal of Ethanobiology and Ethanomidicine, 2013, 9, 24. (DOI: https://doi.org/10.1186/17464269-9-24).

4. B.P Gaire, R. Lamichhane, C.B. Sunar, A. Shilpakar, S. Neupane, S. Panta. Phytochemical Screening and Analysis of Antibacterial and Antioxidant Activity of Ficus auriculata (Lour.) Stem Bark, Pharmacognosy Journal, 2011, 3, 49-55. (DOI: https://doi.org/10.5530/pj.2011.21.8).

5. R.M. Kunwar, R.W. Bussamann. Ficus (Fig) Species in Nepal: A Review of Diversity and Indigenous Tree, Lyonia A Journal of Ecology and Application, 2006, 11, 85-97.

6. G. Niroula, N.B. Singh. Religion and Conservation: A Review of Use and Protection of Sacred Plants and Animals in Nepal, Journal of Institute of Science and Technology, 2015, 20(2), 61-66. (DOI: https://doi.org/10.3126/jist. v20i2.13950).

7. S. Pant, N. Dhami, I. R. Pant. Wild Edible Plants of Lekham Area, Darchula Farwestern Nepal, Scientific World, 2005, 3(3), 73-77.

8. S. Singh. Ethnobotanical Study of Wild Plants of Parsa District, Nepal, Ecoprint: An International Journal of Ecology, 2017, 24, 1-12. (DOI: https://doi.org/10.3126/eco.v24i0.20641)

9. S. Gupta, R. Acharya. Ethnomedicinal Claims of Ficus semicordata Buch.-Ham. ex Sm.: A Review, International Journal of Green Pharmacy, 2018, 12(1), 206-213. (DOI: http://dx.doi.org/10.22377/ijgp.v12i01.1621).

10. M. Goerge, L. Joseph, N.M. Pal. Ficus auriculata: A Pharmacological Update, International Journal of Current Search and Academic Review, 2016, 4(7), 26-31. (DOI: http://dx.doi.org/10.20546/ijcrar.2016.407.003)

11. S. Saklani, S. Chandra. Antimicrobial Activity, Nutritional Profile and Quantitative Fraction of Ficus plamata, International Journal of Science and Research, 2011, 2, 332-337.

12. A. El-Fishway, R. Zayed, S. Afifi. Phytochemical and Pharmacological Studies of Ficus auriculata Lour, Journal of Natural Products, 2011, 4, 184-195.

13. C. Tamuly, R. Buragohain, M. Hazarika, J. Bora, P.R Gajurel. Assessment of Antioxidant Activity of Six Ficus Species - Underutilized Fruits of Arunachal Pradesh in North East India, International Journal of Fruit Science 2015, 15, 85-99. (DOI: https://doi.org/10.1080/15538362.2014.931174)

14. A. Hassan, Z. Akmal, N. Khan. The Phytochemical Screening and Antioxidants Potential of Schoenoplectus triqueter L. Palla, Journal of Chemistry, 2020. (DOI: https://doi.org/10.1155/2020/3865139).

15. M. Balouiri, M. Sadiki, S. K. Ibsouda. Methods of In-vitro Evaluating Antimicrobial Activity: A Review, Journal of Pharmaceutical Analysis, 2016, 6(2), 71-79. (DOI: https://doi.org/10.1016/j.jpha.2015.11.005)

16. E. Birben, U. Murat, S. C. Sackesen, S. Erzurum, O. Kalayei. Oxidative Stress and Antioxidant Defense, World Allergy Organization Journal, 2012, 5(1), 9-19. (DOI: https://doi.org/10.1097/wox.0b013e3182439613)

17. N. Ghosh. A Das, S. Chaffee, S. Roy, C.K. Sen. Chapter 4 - Reactive Oxygen Species, Oxidative Damage and Cell Death, Immunity and Inflammation in Health and Disease, Academic Press, 2018. (DOI: https://doi.org/10.1016/B978-0-12805417-8.00004-4).

18. B. Uttara, A.V. Singh, P. Zamboni, R.T. Mahajan. Oxidative Stress and Neurodegenerative Diseases: A Review of Upstream and Downstream Antioxidant Therapeutic Options, Current Neuropharmacology, 2009, 7(1), 65-74. (DOI: https://dx.doi.org/10.2174\%2F157015909787602823).

19. D. Sanna, G. Delogu, M. Mulas. Determination of Free Radical Scavenging Activity of Plant Extracts Through DPPH Assay: An EPR and UV- Vis Study, Food and Analytical Methods, 2012, 5, 759-766. (DOI: https://doi.org/10.1007/ s12161-011-9306-1). 